\title{
Multiethnic Training in Residency: A Survey of Dermatology Residents
}

\author{
Abigail Cline, MD, PhD; Randi P. Winter, MD; Shadi Kourosh, MD, MPH; Susan C. Taylor, MD; \\ Molly Stout, MD; Valerie Callender, MD; Amy J. McMichael, MD
}

\section{PRACTICE POINTS}

- To treat the ever-changing demographics of patients in the United States, dermatologists must receive adequate exposure and education regarding dermatologic conditions in patients from various ethnic backgrounds.

- Dermatology residents from less diverse regions are more likely to agree that dedicated clinics and rotations are important to gain competence compared to those from more diverse regions.

- In areas with less diversity, dedicated multiethnic skin clinics and faculty may be more important for assuring an adequate residency experience.
Individuals with skin of color make up the majority of the world's population and a rapidly expanding section of the US population. Future dermatologists must be knowledgeable about dermatologic conditions presenting in patients of various ethnic backgrounds. A 10-question survey was emailed to 109 dermatology residency programs to assess if dermatologists in-training feel that their residency curriculum sufficiently gives them exposure to and education on patients with skin of color. Forty-three residents completed the survey from 5 regions of the United States. Resident responses differed by region. Residents from areas with less diversity were more likely to agree that dedicated skin of color clinics and rotations are important to gain competency compared to residents from areas with more diversity.

Cutis. 2020;105:310-313.

ermatologic treatment of patients with skin of color offers specific challenges. Studies have reported structural, morphologic, and physiologic distinctions among different ethnic groups, ${ }^{1}$ which may account for distinct clinical presentations of skin disease seen in patients with skin of color. Patients with skin of color are at increased risk for specific dermatologic conditions, such as postinflammatory hyperpigmentation, keloid development, and central centrifugal cicatricial alopecia., ${ }^{2,3}$ Furthermore, although skin cancer is less prevalent in patients with skin of color, it often presents at a more advanced stage and with a worse prognosis compared to white patients. ${ }^{4}$

Individuals with skin of color make up the majority of the world's population and a rapidly expanding portion of the US population. By the year 2044, more than half of all Americans are projected to belong to an ethnic group that is currently a minority. By 2060, the population of citizens identifying with 2 or more races will increase by $226 \%$, the Asian population is projected to grow by $128 \%$, the Hispanic population will increase by $115 \%$, and the black population will increase by $42 \% .^{5}$ The racial and ethnic composition of the United States is evolving, and dermatologic care must evolve accordingly to address patients' unique concerns. It is essential for future dermatologists to be knowledgeable about dermatologic conditions presenting in patients of various ethnic backgrounds.

Prior studies have demonstrated the need for increased exposure, education, and training in diseases pertaining to skin of color in US dermatology residency programs. ${ }^{6-8}$ The aim of this study was to assess if dermatologists intraining feel that their residency curriculum sufficiently educates them on the needs of patients with skin of color.

\section{Methods}

A 10-question anonymous survey was emailed to 109 dermatology residency programs to evaluate the attitudes of dermatology residents about their exposure to patients with skin of color and their skin-of-color curriculum. The study included individuals 18 years or older who were current residents in a dermatology program accredited by the Accreditation Council for Graduate Medical Education. Responses were measured on a 1 to 3

Drs. Cline and Winter are from the Center for Dermatology Research, Department of Dermatology, Wake Forest School of Medicine, Winston-Salem, North Carolina. Dr. Kourosh is from the Department of Dermatology, Massachusetts General Hospital, Boston. Dr. Taylor is from the Department of Dermatology, University of Pennsylvania, Philadelphia. Dr. Stout is from the Department of Dermatology, Northwestern Feinberg School of Medicine, Chicago, Illinois. Dr. Callender is from Callender Dermatology and Cosmetic Center, Glenn Dale, Maryland. Dr. McMichael is from the Department of Dermatology, Wake Forest Baptist Medical Center, Winston-Salem.

The authors report no conflict of interest.

Correspondence: Abigail Cline, MD, PhD (aecline25@gmail.com). 
Likert scale, ranging from agree, neutral, and disagree. Data were analyzed using the Fisher exact test, and the statistical significance was set at $P<.05$.

\section{Results}

Forty-three dermatology residents completed the survey. Respondents self-selected their regions, with 8 (19\%) from the Northeast (NE), 7 (16\%) from the Southeast (SE), 12 (28\%) from the Midwest (MW), 8 (19\%) from the Southwest (SW), and 8 (18\%) from the Northwest (NW)(Table 1). Overall, 31 (72\%) respondents agreed that their practice treats a diverse patient population. Respondents who agreed most often were from the NE, SE, and SW. Less than two-thirds of respondents from the MW agreed, and only half of respondents from the NW agreed (Table 2). Although 37\% of all respondents agreed that a dedicated multiethnic skin clinic is important for residents, 5 (63\%) NE residents disagreed with this statement compared to $5(42 \%)$ MW residents and 5 (63\%) NW residents who agreed $(P<.005)$. Overall, 39 (91\%) respondents agreed that dedicated lectures on skin conditions in skin of color patients are important to gain competence in treating patients. Only 4 respondents were neutral to this question, 2 (17\%) MW residents and 2 (25\%) SW residents. When asked if reading textbook chapters on multiethnic skin is important to gain competence, 36 (83\%) respondents agreed. Two respondents disagreed, 1 (13\%) from the NE and $1(8 \%)$ from the MW. Overall, $23 \%$ of respondents agreed that a rotation dedicated to skin of color is important to build competency. There was a significant difference in responses between the NE and MW $(P=.032)$ and between the NE and NW $(P=.019)$. Furthermore, 19 (44\%) respondents agreed that having a faculty member or departmental expert is important for residents to gain competence in treating conditions affecting skin of color. Again, there was a significant difference in responses between the NE and MW $(P=.003)$ and between the SE and MW $(P=.009)$.

When asked the number of hours of lecture per month necessary to gain competence in conditions affecting patients with skin of color, $67 \%$ agreed that 1 to

\section{TABLE 1. Regional Variation of Survey Respondents $(\mathrm{N}=43)$}

\begin{tabular}{ll}
\hline US Region & No. of Respondents (\%) \\
\hline Northeast & $8(18.6)$ \\
\hline Southeast & $7(16.3)$ \\
\hline Midwest & $12(27.9)$ \\
\hline Southwest & $8(18.6)$ \\
\hline Northwest & $8(18.6)$ \\
\hline
\end{tabular}

5 hours was sufficient (Table 3). There were significant differences in the responses between the NE and SE $(P=.024)$ and the SE and MW $(P=.007)$. Of all respondents, $53 \%$ reported 1 to 5 months of clinical training are needed to gain competence in treating conditions affecting patients with skin of color, with significant differences in responses between the NE and MW $(P<.001)$, the NE and SW $(P=.019)$, and the SE and MW $(P=.015)$ (Table 4).

\section{Comment}

Responses varied by practicing region. Less ethnically diverse regions, such as the MW and NW, were more likely to agree that dedicated clinics and rotations are important to gain competence compared to more ethnically diverse regions such as the NE, SE, and SW. Overall, more residents reported that dedicated lectures and textbook chapters were important to gain competency compared to dedicated clinics or rotations.

Although interactive lectures and textbook readings are important for obtaining a foundational understanding of dermatologic disease, they cannot substitute for clinical interactions and hands-on experience treating patients with skin of color. ${ }^{9}$ Not only do clinical interactions encourage independent reading and the study of encountered diagnoses, but intercommunication with patients may have a more profound and lasting impact on residents' education.

Different regions of the United States have varying distributions of patients with skin of color, and dermatology residency program training reflects these disparities. ${ }^{6}$ In areas of less diversity, dermatology residents examine, diagnose, and treat substantially fewer patients with skin of color. The desire for more diverse training supports the prior findings of Nijhawan et $\mathrm{al}^{6}$ and is reflected in the responses we received in our study, whereby residents from the less ethnically diversified regions of the MW and NW were more likely to agree that clinics and rotations were necessary for training in preparation to sufficiently address the needs of patients with skin of color.

One way to compensate for the lack of ethnic diversity encountered in areas such as the MW and NW would be to develop educational programs featuring experts on skin of color. ${ }^{6}$ These specialists would not only train dermatology residents in areas of the country currently lacking ethnic diversity but also expand the expertise for treating patients with skin of color. Additionally, dedicated multiethnic skin clinics and externships devoted solely to treating patients with skin of color could be encouraged for residency training. ${ }^{6}$ Finally, community outreach through volunteer clinics may provide residents exposure to patients with skin of color seeking dermatologic care. ${ }^{10}$

This study was limited by the small number of respondents, but we were able to extract important trends and data from the collected responses. It is possible that respondents felt strongly about topics involving 
TABLE 2. Regional Variation in Resident Perceptions Regarding Skin-of-Color Curriculum $(\mathrm{N}=43)$

\begin{tabular}{|c|c|c|c|c|}
\hline \multirow[b]{2}{*}{ Question } & \multirow[b]{2}{*}{ Region } & \multicolumn{3}{|c|}{ No. of Respondents (\%) } \\
\hline & & Agree & Neutral & Disagree \\
\hline \multirow{5}{*}{$\begin{array}{l}\text { My practice setting treats a patient population that is } \\
\text { diverse in skin types and ethnicities }\end{array}$} & NE & 7 (87.5) & $0(0)$ & $1(12.5)$ \\
\hline & SE & $6(85.7)$ & $0(0)$ & $1(14.3)$ \\
\hline & MW & 7 (58.3) & $2(16.7)$ & $3(25.0)$ \\
\hline & SW & 7 (87.5) & $1(12.5)$ & $0(0)$ \\
\hline & NW & $4(50.0)$ & $2(25.0)$ & $2(25.0)$ \\
\hline \multirow{5}{*}{$\begin{array}{l}\text { A dedicated multiethnic skin clinic is important for } \\
\text { residents to become competent in treating skin conditions } \\
\text { affecting skin of color and/or multiethnic skin }\end{array}$} & NE & $0(0)$ & $3(37.5)$ & $5(62.5)$ \\
\hline & SE & $4(57.1)$ & $1(14.3)$ & 2 (28.6) \\
\hline & MW & $5(41.7)$ & $6(50)$ & $1(8.3)$ \\
\hline & SW & $2(25.0)$ & $5(62.5)$ & $1(12.5)$ \\
\hline & NW & $5(62.5)$ & 3 (37.5) & $0(0)$ \\
\hline \multirow{5}{*}{$\begin{array}{l}\text { A dedicated rotation is important for residents to become } \\
\text { competent in treating skin conditions affecting skin of color } \\
\text { and/or multiethnic skin }\end{array}$} & NE & $0(0)$ & $3(37.5)$ & $5(62.5)$ \\
\hline & SE & $2(28.6)$ & 2 (28.6) & $3(42.9)$ \\
\hline & MW & $3(25.0)$ & $8(66.7)$ & $1(8.3)$ \\
\hline & SW & $2(25.0)$ & $3(37.5)$ & $3(37.5)$ \\
\hline & NW & $3(37.5)$ & $5(62.5)$ & $0(0)$ \\
\hline \multirow{5}{*}{$\begin{array}{l}\text { Dedicated lectures on skin conditions affecting skin of } \\
\text { color and/or multiethnic skin are important for residents } \\
\text { to become competent in treating skin conditions affecting } \\
\text { skin of color and/or multiethnic skin }\end{array}$} & NE & $8(100)$ & $0(0)$ & $0(0)$ \\
\hline & SE & $7(100)$ & $0(0)$ & $0(0)$ \\
\hline & MW & 10 (83.3) & 2 (16.7) & $0(0)$ \\
\hline & SW & 6 (75.0) & 2 (25.0) & $0(0)$ \\
\hline & NW & 8 (100) & $0(0)$ & $0(0)$ \\
\hline \multirow{5}{*}{$\begin{array}{l}\text { A faculty member or departmental expert is important } \\
\text { for residents to become competent in treating skin } \\
\text { conditions affecting skin of color and/or multiethnic skin }\end{array}$} & NE & $2(25.0)$ & $1(12.5)$ & 5 (62.5) \\
\hline & SE & 5 (71.4) & $0(0)$ & 2 (28.6) \\
\hline & $\mathrm{MW}$ & $5(41.7)$ & 7 (58.3) & $0(0)$ \\
\hline & SW & 3 (37.5) & 3 (37.5) & $2(25.0)$ \\
\hline & NW & $4(50.0)$ & $4(50.0)$ & $0(0)$ \\
\hline \multirow{5}{*}{$\begin{array}{l}\text { Reading textbook chapters on multiethnic skin is } \\
\text { important for residents to become competent in } \\
\text { treating skin conditions affecting skin of color and/or } \\
\text { multiethnic skin }\end{array}$} & $\mathrm{NE}$ & $6(75.0)$ & $1(12.5)$ & $1(12.5)$ \\
\hline & SE & $5(71.4)$ & 2 (28.6) & - \\
\hline & MW & $11(91.7)$ & $0(0)$ & 1 (8.3) \\
\hline & SW & 7 (87.5) & $1(12.5)$ & $0(0)$ \\
\hline & NW & 7 (87.5) & $1(12.5)$ & $0(0)$ \\
\hline
\end{tabular}

Abbreviations: NE, Northeast; SE, Southeast; MW, Midwest; SW, Southwest; NW, Northwest.

patients with skin of color, and the results were skewed to reflect individual bias. Additional limitations included not asking respondents for program names and population density (eg, urban, suburban, rural). Future studies should be directed toward analyzing how the diversity of the local population influences training in patients with skin of color, comparing program directors' perceptions with residents' perceptions on training in skin of color, and assessing patient perception of residents' training in skin of color.

\section{Conclusion}

In the last decade it has become increasingly apparent that the US population is diversifying and that patients 


\section{TABLE 3. Regional Variation in Preferred Hours of Education Regarding Skin-of-Color Education $(\mathrm{N}=43)$}

\begin{tabular}{|c|c|c|c|c|c|c|c|c|}
\hline \multirow[b]{2}{*}{ Question } & \multirow[b]{2}{*}{ Region } & \multicolumn{7}{|c|}{ No. of Respondents (\%) } \\
\hline & & $\begin{array}{l}0 \\
\text { Hours }\end{array}$ & $\begin{array}{l}1-5 \\
\text { Hours }\end{array}$ & $\begin{array}{l}6-10 \\
\text { Hours }\end{array}$ & $\begin{array}{l}11-15 \\
\text { Hours }\end{array}$ & $\begin{array}{l}16-20 \\
\text { Hours }\end{array}$ & $\begin{array}{l}>20 \\
\text { Hours }\end{array}$ & Skipped \\
\hline \multirow{5}{*}{$\begin{array}{l}\text { How many hours per month of lectures } \\
\text { covering conditions affecting patients } \\
\text { with skin of color and/or multiethnic } \\
\text { skin are needed to become competent } \\
\text { in treating such conditions? }\end{array}$} & $\mathrm{NE}$ & $0(0)$ & $7(87.5)$ & $0(0)$ & $0(0)$ & $1(12.5)$ & $0(0)$ & $0(0)$ \\
\hline & SE & $1(14.3)$ & $2(28.6)$ & $3(42.9)$ & $1(14.3)$ & $0(0)$ & $0(0)$ & $0(0)$ \\
\hline & $\mathrm{MW}$ & $1(8.3)$ & $10(83.3)$ & $0(0)$ & $0(0)$ & $0(0)$ & $0(0)$ & $1(8.3)$ \\
\hline & SW & $0(0)$ & $5(71.4)$ & $1(14.3)$ & $1(14.3)$ & $0(0)$ & $0(0)$ & $0(0)$ \\
\hline & NW & $0(0)$ & $5(62.5)$ & $1(12.5)$ & $1(12.5)$ & $1(12.5)$ & $0(0)$ & $0(0)$ \\
\hline
\end{tabular}

Abbreviations: NE, Northeast; SE, Southeast; MW, Midwest; SW, Southwest; NW, Northwest.

\section{TABLE 4. Regional Variation in Preferred Months of Education Regarding Skin-of-Color Education $(\mathrm{N}=43)$}

\begin{tabular}{|c|c|c|c|c|c|c|c|c|}
\hline \multirow[b]{2}{*}{ Question } & \multirow[b]{2}{*}{ Region } & \multicolumn{7}{|c|}{ No. of Respondents (\%) } \\
\hline & & $\begin{array}{l}0 \\
\text { Months }\end{array}$ & $\begin{array}{l}1-5 \\
\text { Months }\end{array}$ & $\begin{array}{l}6-10 \\
\text { Months }\end{array}$ & $\begin{array}{l}11-15 \\
\text { Months }\end{array}$ & $\begin{array}{l}\text { 16-20 } \\
\text { Months }\end{array}$ & $\begin{array}{l}>20 \\
\text { Hours }\end{array}$ & Skippeo \\
\hline \multirow{5}{*}{$\begin{array}{l}\text { How many clinical training } \\
\text { months treating patients with } \\
\text { skin of color and/or multiethnic } \\
\text { skin are needed to become } \\
\text { competent in treating such } \\
\text { conditions? }\end{array}$} & NE & $3(37.5)$ & $1(12.5)$ & $0(0)$ & $1(12.5)$ & $1(12.5)$ & $1(12.5)$ & $1(12.5)$ \\
\hline & SE & $1(14.3)$ & $3(42.9)$ & $1(14.3)$ & $2(28.6)$ & $0(0)$ & $0(0)$ & $0(0)$ \\
\hline & MW & $0(0)$ & $10(83.3)$ & $0(0)$ & $0(0)$ & $0(0)$ & $0(0)$ & $2(16.7)$ \\
\hline & SW & $0(0)$ & $5(62.5)$ & $2(25.0)$ & $0(0)$ & $0(0)$ & $0(0)$ & $1(12.5)$ \\
\hline & NW & $0(0)$ & $4(50.0)$ & $1(12.5)$ & $1(12.5)$ & $0(0)$ & $1(12.5)$ & $1(12.5)$ \\
\hline
\end{tabular}

Abbreviations: NE, Northeast; SE, Southeast; MW, Midwest; SW, Southwest; NW, Northwest.

with skin of color will comprise a substantial proportion of the future population, ${ }^{8,11}$ which emphasizes the need for dermatology residency programs to ensure that residents receive adequate training and exposure to patients with skin of color as well as the distinct skin diseases seen more commonly in these populations. ${ }^{12}$

\section{REFERENCES}

1. Luther N, Darvin ME, Sterry W, et al. Ethnic differences in skin physiology, hair follicle morphology and follicular penetration. Skin Pharmacol Physiol. 2012;25:182-191.

2. Shokeen D. Postinflammatory hyperpigmentation in patients with skin of color. Cutis. 2016;97:E9-E11.

3. Lawson $\mathrm{CN}$, Hollinger J, Sethi S, et al. Updates in the understanding and treatments of skin \& hair disorders in women of color. Int JWomen's Dermatol. 2017;3:S21-S37.

4. Hu S, Parmet Y, Allen G, et al. Disparity in melanoma: a trend analysis of melanoma incidence and stage at diagnosis among whites, Hispanics, and blacks in Florida. Arch Dermatol. 2009; 145:1369-1374.

5. Colby SL, Ortman JM; US Census Bureau. Projections of the Size and Composition of the U.S. Population: 2014 to 2060. Washington, DC:
US Census Bureau; 2014. Current Population Reports, P25-1143. https://census.gov/content/dam/Census/library/publications/2015 /demo/p25-1143.pdf. Published March 2015. Accessed May 13, 2020.

6. Nijhawan RI, Jacob SE, Woolery-Lloyd H. Skin of color education in dermatology residency programs: does residency training reflect the changing demographics of the United States? J Am Acad Dermatol. 2008;59:615-618

7. Pritchett EN, Pandya AG, Ferguson NN, et al. Diversity in dermatology: roadmap for improvement. J Am Acad Dermatol. 2018;79:337-341.

8. Pandya AG, Alexis AF, Berger TG, et al. Increasing racial and ethnic diversity in dermatology: a call to action. J Am Acad Dermatol. 2016;74:584-587.

9. Ernst H, Colthorpe K. The efficacy of interactive lecturing for students with diverse science backgrounds. Adv Physiol Educ. 2007;31:41-44.

10. Allday E. UCSF opens 'skin of color' dermatology clinic to address disparity in care. San Francisco Chronicle. March 20, 2019. https://www.sfchronicle.com/health/article/UCSF-opens-skin-of -color-dermatology-clinic-13704387.php. Accessed May 13, 2020.

11. Van Voorhees AS, Enos CW. Diversity in dermatology residency programs. J Investig Dermatol Symp Proc. 2017;18:S46-S49.

12. Enos CW, Harvey VM. From bench to bedside: the Hampton University Skin of Color Research Institute 2015 Skin of Color Symposium. J Investig Dermatol Symp Proc. 2017;18:S29-S30. 